\title{
Innovating innovation, my infundibular
}

\author{
Esa Litelcoque
}

It's reinvent the wheel time in the good old NHS as we are asked by those who changed sides from being 'one of us' to being 'one of them' to embrace innovation. Well, that's nothing new for us in general practice where the wheel of innovation just keeps on turning, as it has done for years.

Who was it that was denying antibiotics to the "cough and coldy' brigade before the seed of antibiotic resistance was sewn? Who was it that added 'Your Responsibilities' to 'Your Rights' in the Patient's Charter? And who was it that welcomed counsellors into primary care so patients had someone who actually wanted to listen to their woes, and hardworking doctors were rewarded with some respite from heartsink patients? That's right, GPs.

But always ready to serve, at my practice we're innovating even more. In the true spirit of patient involvement and participation we're asking our patients what innovative ideas they want to see taken forward. Ideas have been sought, whittled down, and here are the Top 10 finalists from which three will receive the accolade of our 'Innovation Mark'.

1 Dr $X$ to shave off the bushy 1980s moustache. Not because it's no longer fashionable - although that would be reason enough - but because it scares small children, is a magnet for food debris, and our hearing-impaired patients complain they can't see to lip-read.

2 Implant again. A recycling scheme to lessen waste and protect fish and consequently the human race. When a woman requests removal of her contraceptive implant, rather than just throwing it away it can be reused. After all, there could be a year or more of use left in it.

3 Bring and buy. Medical supplies gather in patients' homes making it hard for caring doctors and nurses to know exactly what a patient is using and what they are simply hoarding. Having these items around puts patients' health at risk, as many have no idea whether they should be using the item at all, or indeed what the item is for in the first place. These items can now be sold at our weekly 'bring and buy' sale. This occupies the patients whilst they wait for their appointment (and lessens the chance of complaints to reception staff); patients feel they're getting added value for something since they're paying for it (rather than the usual practice of just giving it to each other to try); and the practice takes a percentage of the profit.

4 Incredibly low-energy light bulbs. The well-known benefit of these is energy conservation, obviously. However, other benefits include being able to convince a patient that there isn't anything to see so they shouldn't be worried and, importantly, the patient not being able to see the bored expression on their GP's face.

5 Patient-held records. I've always liked this idea because it neatly shifts the responsibility onto the patient and leaves me blame-free when notes go missing. We're going to sell a 'bag for life' to those with extensive notes,

J Fam Plann Reprod Health Care 2009; 35(4): 255

Prickly Horn Surgery, Grasping de Nettle, UK

Esa Litelcoque, MRCGP, General Practitioner and for a small fee a 'home collection and return' service for those whose notes are so enormous they couldn't possibly carry them even in an in-flight trolley bag. In line with modern day protocols, delivery can be any time between $7.00 \mathrm{am}$ and $8.00 \mathrm{pm}$ (our practice opening hours), which should mean people are trapped at home waiting for their notes delivery and so can't come and trouble us at the practice.

6 No more home visits. Not because we are lazy. It's because we're concerned about the environment and want to reduce our carbon footprint by making fewer unnecessary journeys in our enormous $4 \times 4 \mathrm{~s}$. The goal is to make patients feel really guilty for even thinking about asking for a home visit. This will be accompanied by a local media campaign to help enrol the support of all our patients, thereby strengthening the message: "You should be ashamed of yourself for even thinking about requesting a home visit, let alone allowing yourself to reach a point where you may genuinely need one. Think about the children of the future, why don't you".

7 Guess the diagnosis. Introducing the Internet in the waiting room. We'll be challenging patients to see how close they get to accurately diagnosing their complaint. Not only will this teach them how clever we doctors are, it will also make us heroes in their eyes as we reassure them that they don't have that rare and fatal disease, but simply dry skin that can easily be treated with this lovely soothing cream.

8 Patient complaint system. A little twist here. This adapted system allows members of the practice to complain about a patient. The patient then has to acknowledge the complaint within 2 days and provide a convincing explanation for why they did what they did. The patient has to provide a report of their investigation into the episode within 10 days. During this time they will be sent letters, faxes and e-mails from friends of the practice, the PCT, the local MP and anyone else who wishes to join in and have a go. This system, if successful, will be extended to enable patients to make formal complaints about other patients too.

9 Recycle your cap box. We're talking about contraceptive caps and diaphragms here. Now there's no need to just throw it away. A good wash will mean someone else will get a valuable and eye-watering insight into the world of the escapologist, and may learn a new way to self-pleasure into the bargain.

10 Bring your own chair. Do you really need to sit down? Hasn't the doctor advised you to keep active? Well, here's your opportunity to do so. We've removed the chairs. But if you need to sit down then you'll need to bring your own seat, or join others on our energygenerating static bicycles, conveniently located in each corner of the waiting room, where facing the wall you'll learn how tiresome it is to hear time and time again about how you hardly eat anything so why are you putting on weight.

Of course, none of these innovations will be able to top the most impressive innovation to date in the NHS, namely the driver of innovation actually quitting his government post. None the less, let the games commence; because, after all, a game is all this really is. 